\title{
PIÑERA PREFERIRÍA: ABURRIMIENTO Y REVOLUCIÓN ${ }^{1}$
}

\author{
POR \\ KARINA MiLler \\ Independent Scholar
}

Mucho se ha escrito sobre las condiciones de producción y circulación de los textos del escritor cubano Virgilio Piñera (1912-1979) en la Cuba posrevolucionaria; se ha denominado su situación como "muerte en vida" o lo que él mismo llamó "muerte civil", en referencia al silencio público con respecto a su figura de autor y la prohibición de publicación de sus obras. ${ }^{2}$ Este contexto de aislamiento personal y profesional facilita una lectura alegórica de su escritura, especialmente de los temas de la soledad, el miedo, el absurdo de la vida cotidiana, la fragmentación del cuerpo y la sexualidad velada. Propongo desviarnos de la línea alegórica para considerar ciertas representaciones paradigmáticas y constantes en la escritura de Piñera más allá de su referencia a la situación personal y política del escritor, como categorías de análisis que indagan en la función de una escritura específicamente impolítica (aclaro este término más adelante). En la escritura de Piñera la alegoría es un componente más de la ironía, o si se quiere, un primer nivel de lectura que abre el acceso a una experiencia menos mecánica, menos obvia, y sobre todo menos heroica, que evita las resonancias morales que implica la enunciación de una verdad universal. ${ }^{3}$

1 Este artículo forma parte de un capítulo de mi libro Escrituras Impolíticas: Anti-representaciones de la comunidad en Juan Rodolfo Wilcock, Osvaldo Lamborghini y Virgilio Piñera (en revisión).

2 "No solo estábamos muertos en vida; parecíamos no haber nacido nunca", son las palabras de Antón Arrufat que cita Rita Molinero al referirse a la marginación del período del quinquenio gris (1970-1975) (19).

3 Para una mejor comprensión de este tema, y en particular de las posiciones teóricas críticas de la lectura alegórica de la literatura en Gilles Deleuze y Derek Attridge, ver el ensayo de Gert Buelens y Dominiek Hoens: "Above and Beneath Classification". La problemática de la lectura alegórica como "la regla" y la singularidad del texto como "la excepción" se resuelve en la literatura como "evento": "[Derek] Attridge has argued for a type of reading that does not reduce literature to allegory of meaning. Literature is not something that simply exists-waiting for a theoretician who will use it as an illustration or for a reader who will only understand what he or she already knows-but is an event, something that brings something new into a given situation. This singularity does not turn literature into something that is altogether irrelevant for theory. On the contrary, precisely because it escapes, or at least resists, interpretative schemes, literature forces the reader to question them", 157. 
Me interesa indagar cómo las representaciones de ciertas experiencias, estados y afectos negativos (miedo, aburrimiento, apatía, estupidez) interrumpen la lógica del antagonismo de lo político y la del discurso hegemónico revolucionario basado en la moral del sacrificio, la productividad y el compromiso. Me refiero a la concepción de lo político del teórico alemán Carl Schmitt, en la cual la identificación del enemigo constituye el acto soberano por excelencia, el acto que además define lo político. Schmitt afirma: "The specific political distinction to which political actions and motives can be reduced is that between friend and enemy" (26). Propongo que, junto con otros afectos negativos, la apatía y el aburrimiento constituyen una táctica impolítica para desarmar y desmitificar el discurso de lo político y de un "nosotros" que éste crea. Para mi análisis tomo prestada la noción de categoría de lo impolítico de Roberto Esposito, como abordaje teórico que representa un esfuerzo crítico por eludir la despolitización, la "sobrepolitización" de la exigencia del compromiso social y la "ultrapolitización" de una posición de combate propia de la literatura de los sesenta y setenta en América Latina.

Lo impolítico, como afirma Esposito, interviene facilitando la percepción de la finitud de la política: "La política no siempre tiene consciencia de su propia finitud constitutiva. Está constitutivamente llevada a olvidarla. Lo impolítico no hace otra cosa que "recordársela"' (14). Lo impolítico, entonces, afirma que la política no puede trascenderse a sí misma. Es decir, insiste en que la política tiene un "fin" en el doble sentido de que es finita (limitada) y tiene un objetivo, y por lo tanto no puede ser "teologizada". Esta insistencia en la imposibilidad de trascendencia de la política, no se traduce sin embargo en una propuesta, en una utopía, en una nueva valoración de la política. "Lo impolítico es crítica del encantamiento" (35) anota Esposito, y es precisamente en este punto en que me interesa leer los textos de Piñera como una crítica (pero una crítica impolítica, es decir, sin propuesta, sin discurso utópico) al encantamiento de la política que determinó la literatura latinoamericana-y en particular la Cubana- de los años sesenta y setenta.

En lo que sigue, analizo las novelas Pequeñas maniobras (1963) y Presiones y diamantes (1967), publicadas en un período en el que se institucionaliza en Cuba un endurecimiento ideológico y una política cultural con formas de regulación cada vez más rígidas, que tiene su momento nefasto en 1971 con la "declaración de culpas" de Heriberto Padilla y la declaración del Primer Congreso Nacional de Educación y Cultura en la Habana ese mismo año. ${ }^{5}$

4 Susan Buck-Morss toma la definición de lo político de Schmitt y afirma: "To define the enemy is, simultaneously, to define the collective. Indeed defining the enemy is the act that brings the collective into being", 9 (énfasis del autor).

5 Thomas Anderson señala que la novela fue escrita en 1958, cuando Piñera estaba en Argentina, después del golpe de Estado a Perón. Creo que, por una lado, las circunstancias políticas de su contexto de producción, y las de su contexto de publicación en el 63', son significativas para una lectura (im)política.

Revista Iberoamericana, Vol. LXXXII, Núm. 257, Octubre-Diciembre 2016, 819-836 ISSN 0034-9631 (Impreso)

ISSN 2154-4794 (Electrónico) 
Presiones y diamantes es la historia de "la gran conspiración de la tierra" como "resultado lógico de las grandes presiones". La gente comienza a encontrar maneras de escapar a las presiones de la vida (juegan canasta, mascan chicle, se esconden, se congelan). Por último, optan por meterse en unos "capuchones" inflados y lanzarse al espacio para después desintegrarse (hay también otras teorías que afirman que se lanzaron al mar o que se instalaron en otro planeta). En definitiva, es la historia de cómo desaparece la humanidad por voluntad propia. Una primera lectura alegórica sugiere que la novela se refiere a las presiones del gobierno y la sociedad, a la imposibilidad de cambio -y de la revolución- y también a las dificultades de expresión en una sociedad en la cual nadie quiere hablar y mucho menos escuchar al otro. Esta lectura es sin duda política, ya que estructura la interpretación en las correspondencias entre literatura y sociedad, y las implicancias de sentido de la primera respecto a la segunda. Como los temas son políticos, la literatura cumple una función sesgada de denuncia o comentario. Sin embargo, me interesa desviarnos de esta lectura e indagar de qué manera se desarregla la narrativa política para ser reemplazada por un absurdo que la desfamiliariza. Específicamente, qué figuras y representaciones funcionan como paradigmas que bloquean la lógica de lo político, y cómo se resemantiza su retórica hegemónica. No queda otra opción entonces que indagar en el chicle, la canasta, el hielo y los capuchones de aire.

El protagonista de la novela conversa en un bar con un desconocido que le habla de las "presiones", de cómo los seres humanos presionan y son presionados, ya que nadie puede escapar a este mecanismo "presionador”; el desconocido lo interpela: “QQué tiene usted que decir de esta presión escandalosa? ¿Está conforme con ella? O por el contrario, ¿piensa rebelarse?” (12). Estas preguntas “a quemarropa” (11) producen un sujeto "presionado" que se encuentra en una sociedad cada vez más "presionada", donde los efectos de la presión hacen que los sujetos se aíslen cada vez más hasta desaparecer completamente (las repeticiones en la novela de las palabras "presión", "presionador", "presionado", "presionófilo", etc., forman parte también del "efecto de presión" hacia el lector). El protagonista, que busca en vano la solución al problema de las presiones y que, a su vez, se siente presionado, simula la figura del héroe, en este caso frustrado, de cuya impotencia no se deriva ninguna propuesta o solución utópica para terminar con la "conspiración". Es evidente que encarna la figura del anti-héroe que, de la misma manera que el protagonista de Pequeñas maniobras, siente hastío y apatía frente a lo absurdo de la vida: “[...] el secreto está en dejarnos gastar por la vida hasta convertirnos en un montón de cenizas” (22), dice Sebastián. La apatía impide la comunicación y el contacto humano en general, los cuales son reemplazados primero por el chicle y la canasta y después por el encogimiento, el hielo y los capuchones.

Revista Iberoamericana, Vol. LXXXII, Núm. 257, Octubre-Diciembre 2016, 819-836 ISSN 0034-9631 (Impreso)

ISSN 2154-4794 (Electrónico) 
Presiones y diamantes narra la progresiva desaparición de los vínculos afectivos y sociales, que se desintegran rápidamente una vez eliminada una figura fundamental de sociabilidad: la conversación. La inactividad, la apatía y el vacío espiritual comienzan con un simulacro; la mascada masiva y pasiva de chicles que parodian el habla en silencio, un movimiento gestual que no comunica pero que posee aún un sentido de mímica:

Por sucesivas eliminaciones habíamos arribado a la impavidez [...] la comunicación resultaba tan precaria que cada vez más las palabras querían decir menos y ya se notaba el temor de unos y de otros a aventurarse en los abismos de la conversación. Un modo de llenar las lagunas era la continua masticación de chicles. ¿Sería posible que el hombre hubiese fabricado un producto que recordaba la masticación de la vaca? (25)

El miedo a la conversación que busca solucionarse con la masticación del chicle tiene sin embargo un límite; terminado el chicle, empieza la conversación. No obstante, ésta se hace imposible porque a la masticación se le agrega otro simulacro de reunión: el juego de canasta. Rumiar chicle y jugar canasta representan todavía un aislamiento en comunión, es decir, la gente se congrega aunque sea solamente para reproducir los gestos vacíos de masticación e intercambio de cartas; este estado es también una clave para leer la ética de escritura de Piñera. El "efecto anestésico" (31) del juego tiene una función principal: "Todo dolor moral es 'dormido' por la canasta [...]” (31), explica Raymond al protagonista de la novela. En una primera fase entonces, el silencio y la imposibilidad de comunicación con el prójimo marcan el rumbo de la conspiración. En una lectura (política) alegórica, se interpretaría este silencio como una alusión a la represión que ejerció el aparato burocrático del Estado en Cuba, y en especial a la situación de Piñera en ese contexto político. Sin embargo, y como señala Althusser: "Now this is quite a familiar and banal discourse, but at the same time quite a surprising one" (51). Al examinar los sucesos que llevan a la conspiración podemos identificar una paradoja en la lógica de los hechos: la definición misma de conspiración conlleva un sentido de comunidad y comunicación entre los conspiradores, que, por un lado se ponen de acuerdo en un plan común para derrocar o destituir un sistema (político, social, económico, de poder) y por otro, en el que se hallan implícitas la nociones de acción y la de ideología; dos conceptos que precisamente no aparecen en la novela. El "efecto anestésico" del chicle y la canasta es lo contrario de la conspiración; por lo tanto, una lectura alegórica no alcanza a captar las significaciones impolíticas del texto, ni puede identificar la paradoja en la interpretación política. Esta paradoja sugiere una crisis de representación que es justamente propia de lo impolítico, el "efecto anestésico" de Presiones y diamantes (y también, como veremos de Pequeñas maniobras) pone en escena la negación de la correspondencia entre bien y poder: el complot no supone una revolución o una toma de poder, sino que justamente desfamiliariza la lucha política, la vuelve absurda y de esta manera, evade asignarle un valor, niega su trascendencia y la

Revista Iberoamericana, Vol. LXXXII, Núm. 257, Octubre-Diciembre 2016, 819-836 ISSN 0034-9631 (Impreso)

ISSN 2154-4794 (Electrónico) 
posibilidad utópica de un nuevo sistema o propuesta ideológica propias de la revolución. Es, en definitiva, un complot para la nada. Esposito identifica en la categoría de lo impolítico una "indisponibilidad a sostener tanto la ley del poder como el poder de la ley", que se traduce en la anti-representación de la comunidad como plenitud, o la imposibilidad de universalización discursiva de un particular. Este punto es fundamental para una lectura desde la categoría de lo impolítico: la negación a la representación en la modalidad de teología política en la que el poder es bien, "su traducción política" (33).

¿En qué sentido decimos que evade asignarle un valor a la lucha política? La conspiración, de la misma manera que, por ejemplo, "la causa por el chocolate" en la novela La carne de René (1952), ${ }^{6}$ ironiza y vuelve absurdo los antagonismos propios de lo político, al mismo tiempo que, banalizando y desfamiliarizando los significantes vacíos de la retórica política (rebelión, "Causa", conspiración, lucha, libertad, persecución, presión, etc.), bloquea toda trascendencia de su campo de significación, muestra su artificialidad y la limita a su ser lo que es. Esta operación no implica, sin embargo, ninguna propuesta ideológica (es decir, no le asigna un valor); en Presiones y diamantes la humanidad desaparece por voluntad propia pero paradójicamente llevada por la apatía, el tedio y la inactividad.

Después del juego de canasta se pone de moda el "encogimiento" en el cual las personas literalmente se repliegan sobre sí mismas, pero como si este aislamiento no fuera del todo suficiente la etapa siguiente de la conspiración es la "hibernación" en la que el viajero se desplaza no en el espacio, sino en el tiempo, congelado en un bloque de hielo. "Es un modo de existir sin saberlo", dice Henry al protagonista de Presiones $y$ diamantes "Qué quieres [...] la gente tiene derecho a defenderse, la gente suprime aquello que la mata, la gente no quiere problemas, quiere vivir sin problemas" (50), afirma Henry. El viaje congelado es lo contrario de un viaje, así como la conspiración es lo contrario de una conspiración, y el héroe de la historia es un antihéroe: "he decidido convertirme en agitador público" (71), declara pero en ese momento, frustrado por la indiferencia de la gente ante sus prédicas, abandona su meta cuando Alberto le revela que el pueblo ha empezado a esconderse del "Presionador". Acto seguido al ocultamiento, todo el mundo responde solamente con dos palabras: "rouge melé". El lenguaje se reduce al absurdo. ${ }^{7}$ El protagonista se pregunta:

6 El padre explica al hijo la lucha por la "Causa": "-El jefe que ahora me persigue, hace muchos años logró, tras cruenta lucha, abatir al poderoso y feroz jefe que tenía prohibido en sus estados, so pena de muerte, el uso del chocolate. Éste mantenía rigurosamente tal prohibición que se remontaba en el tiempo a siglos. Sus ancestros, los fundadores de la monarquía, habían prohibido el uso del chocolate en sus reinos. Afirmaban que el chocolate podía minar la seguridad del trono. Imagina sus esfuerzos, las luchas que tuvieron lugar durante siglos para impedir el uso de dicho alimento. Millones de personas murieron, otras fueron deportadas [...]", Carne de René 31.

7 El rouge melé tiene semejanzas con lo que Matías Montes Huidobro, en su ensayo "Siervos cubanos" (sobre la obra de teatro "Los siervos", publicada en la revista Ciclón en 1955), denomina "cantinflismo

Revista Iberoamericana, Vol. LXXXII, Núm. 257, Octubre-Diciembre 2016, 819-836 ISSN 0034-9631 (Impreso)

ISSN 2154-4794 (Electrónico) 
Qué me han hecho. Es una broma pesada que me vea reducido a este triste papel de locutor de una ciudad súbitamente enmudecida. [...] Véanme: puedo decir cualquier palabra que se me antoje -taza, plato, sol, paraguas, zapatos, mantel... puedo abrir la Enciclopedia Británica y pronunciar todas las palabras en ella contenidas; puedo decir: Buenos días, ¿Cómo están ustedes, y buenas noches y buenas tardes. (109, énfasis del autor)

Resulta difícil no interpretar este pasaje como un meta-comentario en referencia a la literatura misma y a su imposibilidad de representar o transmitir un mensaje trascendente. Las palabras están a disposición, pero son objetos huecos, incapaces de retener su significado. Simulan - como el chicle, como la canasta, como la hibernaciónun gesto de comunicación que sin embargo se pierde en la apatía general.

La apatía y el aburrimiento representan una subjetividad en choque con el voluntarismo basado en la praxis revolucionaria; y en particular la derivada de la teoría del foco como guerrilla de guerrillas, acción bélica político-militar que pone acento en la movilidad (que expande su campo de acción por medio del adiestramiento y el reclutamiento). Como señala Juan Duchesne-Winter, la teoría de foco “[...] forjó y legó un modelo de producción de subjetividad correspondiente a la composición del sujeto y acción insurgente imprescindible para la acción revolucionaria [...]" (18) impulsada por la idea de fraguar un sujeto revolucionario a toda prueba (16). El análisis que hace Duchesne de la experiencia guerrillera en la memoria político-militar de Ernesto Che Guevara, Pasajes de la guerra revolucionaria, indaga en la forma de representar la constitución moral y física del sujeto revolucionario como guerrero que debe pasar por una serie de pruebas para demostrar su "resistencia sobrehumana". Anota Duchesne:

Cierta ética situacional del guerrero (talante estoico, valor, dignidad ante la muerte, magnanimidad del más fuerte, respeto del vencido, protección del desamparado, auxilio del débil, sacrificio de la vida por los compañeros de armas, etc.) sirve de modelo virtuoso $[\ldots]$ para generar hegemonía. (46)

En lo que sigue se verá cómo, en el otro lado de la narrativa de Guevara que conforma la "ética situacional del guerrero", Piñera contrapone la pasividad ética del aburrimiento y el no compromiso.

dialéctico" marxista: "El "cantinflismo dialéctico" marxista es un sistema mediante el cual se inventa un sistema léxico que empieza por un determinado razonamiento y se distorsiona a través del lenguaje hasta tal punto que no se entiende nada de lo que se está diciendo. Su objetivo único es anular el pensamiento individual mediante una mecánica del lenguaje frente a la cual la única salida posible es negarse a leer", Molinero 191.

Revista Iberoamericana, Vol. LXXXII, Núm. 257, Octubre-Diciembre 2016, 819-836 ISSN 0034-9631 (Impreso) ISSN 2154-4794 (Electrónico) 
La conspiración se inicia con la falta de comunicación colectiva producida por la apatía general. En este contexto las riquezas materiales, el dinero, el diamante más caro del mundo, dejan de tener valor. Incluso las experiencias e intercambios personales, como la conversación y el viaje, son reemplazados por simulacros. La conversación (y el lenguaje en general) se elimina completamente con el "rouge melé" (palabras que consisten en la única respuesta a cualquier pregunta), y el viaje con el congelamiento en un bloque de hielo. Los viajeros esperan no tener nada que contar a su vuelta, sólo les interesa la preparación para la próxima partida. El narrador desespera, no puede comprender los alcances de la situación, la manera en que el absurdo y el sinsentido se han vuelto vida cotidiana. Resulta productivo comparar este narrador, impotente pero con cierta voluntad de cambio, al narrador de Pequeñas maniobras, Sebastián, personaje que evita por todos los medios el compromiso. La apatía colectiva de Presiones $y$ diamantes se ha internalizado a la subjetividad individual en Pequeñas maniobras. $\mathrm{Ni}$ los reclamos políticos, ni las relaciones amorosas o de amistad interesan a Sebastián, y lo que es más, le espantan: "Yo lo subordino todo a las posibles complicaciones [...]" (150), afirma. Anula incluso su boda, y un día antes de la ceremonia se lo comunica a su prometida:

Muy temprano fui a su casa a decirle que no me casaría. Aunque me conozco poco o nada, traté de explicarle mi decisión. [...] En cambio, le hice ver que no me casaba sencillamente porque no podia hacerlo, que no estaba en mí calificar la fuerza oculta que me obligaba a tal decisión. (241, énfasis mío)

Sebastián tiene muchas similitudes con el personaje de la nouvelle de Herman Melville, Bartelby el escribiente, que responde a todas las demandas de su jefe diciendo "preferiría no hacerlo". Esta nouvelle ha sido interpretada como una crítica a la sociedad capitalista (su subtítulo es sugerente: "una historia de Wall Street") como alegoría de ideas marxistas (Reed, Khodambashi, Finetti, entre otros) de alienación, explotación, lucha de clases, trabajo y capital. Es posible también una interpretación de Pequeñas maniobras y de Presiones y diamantes en diálogo con ciertos conceptos del marxismo; en Pequeñas maniobras los conceptos de alienación y de producción son especialmente útiles para interpretar la negación al compromiso y la responsabilidad de Sebastián como alegorías de resistencia y oposición a la política y lo político. En Presiones y diamantes, las ideas de valor, mercancía, y la concepción dialéctica de la historia, también resultan de utilidad para una interpretación alegórica que la relaciona con su contexto de publicación en 1963. Sin embargo, como he declarado, me interesa una lectura que indague más allá de las correspondencias políticas alegóricas entre texto y realidad social. En este sentido, la recurrencia de la experiencia del tedio o aburrimiento en las dos novelas resulta particularmente interesante, especialmente si se contraponen con los paradigmas discursivos de sacrificio (y muerte), trabajo

Revista Iberoamericana, Vol. LXXXII, Núm. 257, Octubre-Diciembre 2016, 819-836 ISSN 0034-9631 (Impreso)

ISSN 2154-4794 (Electrónico) 
(y productividad), y heroísmo (y lucha) propios de los valores revolucionarios y de los valores de lucha política en general. La insistencia en el aburrimiento, expresado en el desinterés generalizado de los personajes en las relaciones afectivas, sociales y políticas, llama la atención a la no representación de los valores mencionados: el sacrificio, basado en la disponibilidad para la muerte; el trabajo, fundado en la idea de productividad; el heroísmo arraigado en la concepción de la moral combativa; y la voluntad política como ética militante. Propongo interpretar la experiencia del tedio en la escritura de Piñera como una alternativa y una negación del discurso hegemónico que imponía la idea de responsabilidad política al campo literario.

Como menciona Quintero-Herencia: "La necesidad de probarse moralmente en un escenario público cifrado por la guerra [...] anota una atmósfera 'moral' de reclamos y afanes demostrativos dirigidos a la 'insuficiencia' política de la práctica literaria en lo revolucionario" (94). Esta insuficiencia anclada en la "discursividad" e inmaterialidad de la literatura frente a la materialidad de la praxis de la revolución es determinante de un antagonismo insalvable.

La figura del tedio está también relacionada con el concepto marxista de alienación, resultado de la mecanización y fragmentación del trabajo industrial inherente al sistema capitalista de producción. La alienación del trabajador es un factor preponderante en la producción de plusvalía, y por lo tanto, en la situación de explotación y la consiguiente lucha de clases, la cual sería revertida a su tiempo por las fuerzas dialécticas de la Historia. La representación del tedio junto con la alienación de las relaciones sociales fragmentadas en pequeñas acciones sin sentido, la inactividad general, cuya puesta en escena en el viaje congelado se despliega como simulacro que anula la experiencia misma de viajar, y el lenguaje como"rouge melé" revierten, por un lado, el sentido de la Historia como destino trascendente, y por otro, anulan la idea de productividad como motor histórico y de cohesión social. El trabajo, el lenguaje y la historia, entonces, son representados como simulacros, acciones mecánicas y fragmentadas en unidades mínimas que fundamentalmente no producen ninguna esencia y constituyen una distopía que desarma la representación de la comunidad como un todo.

El aburrimiento general denota (en Pequeñas maniobras) una falta de compromiso con el mundo y (en Presiones y diamantes) ausencia de sentido universal, en el que nada significa. De esta manera, el tedio de los relatos y los personajes de Piñera tiene similitudes con la apatía del Bartleby el escribiente de Melville, especialmente en su manera de poner en suspenso una narrativa (positiva) de la productividad. Sin embargo, la apatía en la escritura de Piñera no sólo apunta a la interrupción de la retórica de la moral revolucionaria, sino también a una cierta construcción del "enemigo" que amenaza el propio estilo de vida, en la fórmula de Schmitt. Me interesa la lectura de Bartleby desde este punto de vista, que servirá como abordaje teórico a las representaciones de la pasividad y el aburrimiento que se despliegan en la escritura de Piñera. 
"Nada exaspera más a una persona seria que una resistencia pasiva" (9) dice el abogado sobre Bartleby; el relato de Melville va perfilando la manera en que paulatinamente el escribiente se vuelve una amenaza, en una primera instancia para su empleador, por el hecho de no cumplir las tareas requeridas en la oficina; para los otros dos escribientes, que se violentan por la carga de trabajo extra que les toca frente a las "preferencias" de Bartleby; luego para los visitantes de la oficina que observan con mirada crítica lo absurdo de la situación; para el nuevo inquilino que alquila después de que el abogado se muda; y también para todos los que trabajan en el edificio de oficinas que finalmente Bartleby ocupa. El escribiente inspira una serie de reacciones afectivas de parte del abogado que gradualmente se transforman de estupor en piedad, lástima, rechazo: "Mis primeras reacciones habían sido de pura melancolía y lástima sincera, pero a medida que la desolación de Bartleby se agrandaba en mi imaginación, esa melancolía se convirtió en miedo, esa lástima en repulsión" (13, énfasis mío). Bartleby se transforma en una amenaza para la reputación y la salud mental de su empleador: "Temblé pensando que mi relación con el amanuense ya hubiera afectado seriamente mi estado mental" (15). A tal punto Bartleby trastorna el funcionamiento de la oficina, que incluso el lenguaje, y con éste el pensamiento que lo sostiene, comienza a simular, a copiar, a repetir la retórica del oscuro personaje:

Al abrir la puerta vidriera para retirarse, Nippers desde su escritorio me echó una mirada y me preguntó si yo prefería papel blanco o papel azul para copiar cierto documento. No acentuó maliciosamente la palabra preferir. Se veía que había sido dicha involuntariamente. Reflexioné que era mi deber deshacerme de un demente, que ya, en cierto modo, había influido en mi lengua y quizás en mi cabeza y en las de mis dependientes. Pero juzgué prudente no hacerlo de inmediato. (15)

El abogado hace todo lo posible para evitar el enfrentamiento con su peculiar empleado, intenta incluso un acercamiento afectivo, sin resultado: “-¿Pero qué objeción razonable puede tener para no hablar conmigo? Yo quisiera ser un amigo" (14), dice ante el silencio impávido del amanuense. Queda claro así que la amistad es imposible, por lo cual el abogado se plantea: "Entonces hay que hacer algo severo, algo fuera de lo común" (21). En este punto Bartleby ya se ha vuelto una fuerza antagónica para el funcionamiento de la maquinaria productiva de la oficina, una amenaza que exige un "estado de excepción". La relación que el relato de Melville sugiere entre la pasividad y el antagonismo propio de lo político pone en escena interrogantes válidos para pensar la apatía y la pasividad en los personajes de los relatos de Piñera. De la misma manera que en Bartleby el escribiente, la narrativa del cubano se enfoca en la falta de comunicación como mecanismo fundamental que provoca por un lado, la desintegración de los lazos afectivos de la comunidad, y por otro, la pasividad que lleva al hastío: como un "palo" que traba los engranajes productivos que sostienen y

Revista Iberoamericana, Vol. LXXXII, Núm. 257, Octubre-Diciembre 2016, 819-836 ISSN 0034-9631 (Impreso)

ISSN 2154-4794 (Electrónico) 
alimentan el discurso de lo político. Esta pasividad provoca una violencia excesiva y por lo tanto inútil:

Imposible expulsarlo a empujones; inútil sacarlo a fuerza de insultos; llamar a la policía era una idea desagradable; y sin embargo, permitirle gozar de su cadavérico triunfo sobre mí, eso también era inadmisible. ¿Qué hacer? o, si no había nada que hacer, ¿qué dar por sentado? (28)

Creo que estas dos últimas preguntas rondan también las novelas Presiones y diamantes y Pequeñas maniobras. ¿Qué se da por sentado cuando no hay nada que hacer? ¿Qué función queda para el antagonismo de lo político cuando la guerra deja de ser una opción válida? Lo que el abogado vislumbra (lo inútil de la exterminación de Bartleby como enemigo), es en la escritura de Piñera la negación de la violencia hacia el otro, y por sobre todo la negación del compromiso político como antagonismo bélico. Si no existe un Otro (un sistema, una comunidad, una ideología) que pueda ser interpelado por la pregunta por el enemigo, y si la pregunta misma queda flotando, absurdamente, en la apatía, el aburrimiento y la improductividad, la interpelación del enemigo es un planteo imposible y por lo tanto, impolítico. En Presiones y diamantes no se trata de una conspiración en "contra" de un sistema de poder, sino de lo absurdo de la conspiración misma; de tal manera que la narración no despliega valores o afectos positivos con los cuales el lector se pueda identificar, sino por el contrario, una apatía general, una suspensión de la Historia y del conflicto como motor de ésta. Los personajes de estas novelas de Piñera se retiran de la acción de una manera extrema, recuerdan la imagen que Fidel Castro reclama como anti-ejemplo de lo revolucionario cuando afirma, en "La segunda declaración de La Habana", que no es de revolucionarios sentarse en la puerta de su casa para ver pasar el cadáver del capitalismo.

La estupidez como correlato de la apatía se perfila tanto en Piñera como en Melville. Branka Arsic (siguiendo a Gilles Deleuze) analiza la capacidad de pensamiento del escribiente, el esfuerzo del abogado por "leer" en Barlteby alguna señal de actividad en un rostro que está tan inmóvil como sus pensamientos: "An absolute nonpolitical being, Bartleby becomes an almost idiotic figure" (60). La pasividad de la mente se refleja en la impasividad del cuerpo, de esta manera en Presiones y diamantes la masticación mecánica del chicle simula (¿o produce?) la monotonía del pensamiento y como señala el narrador, imita el rumiar de la vaca, metáfora de la estupidez. ${ }^{8} \mathrm{La}$ calificación del escribiente como ser "no-político" llama la atención a la relación entre esta incapacidad de pensamiento y la lógica de lo político. ¿De qué manera la estupidez

8 Arsic relaciona la "falta de labios" en el rostro de Bartleby como una metáfora de su falta de pensamiento: "Such an absence (of the labor of thinking) manifests itself as the negation of the lips themselves. Bartelby's lips are a pale trace of the oblivion of thought, which fails to write itself as a face", 63.

Revista Iberoamericana, Vol. LXXXII, Núm. 257, Octubre-Diciembre 2016, 819-836 ISSN 0034-9631 (Impreso)

ISSN 2154-4794 (Electrónico) 
es una amenaza para la soberanía? ¿Es posible que la estupidez reclame un "estado de excepción"? En Presiones y diamantes los habitantes de la tierra, rumiantes, congelados, jugadores silenciosos de canasta, comienzan a esconderse del "Presionador", para lo cual se ocultan en sus casas y evitan todo contacto con el prójimo. Como una especie de toque de queda autoimpuesto, la gente deja de circular por las calles, situación que simula un estado de guerra. Si bien es la estupidez general, incomprensible para el narrador, y no la guerra, lo que genera este estado de excepción, es el aburrimiento y la apatía que se han contagiado a la población entera los que producen el vaciamiento de sentido del lenguaje (rouge melé) y de la Historia. Estos afectos negativos se vuelven entonces una táctica impolítica, que bloquea el sentido de trascendencia de los valores morales que fundamentan la ideología revolucionaria como motor de la historia, no para proponer otros valores diferentes, o para cumplir la función de denuncia alegorizando un mensaje, sino precisamente para mostrar la artificialidad de esta utopía. Es importante remarcar la relevancia política de esta operación de sentido: lo impolítico no es apolítico ni anti-político, sino que opera desde los límites de la política, es decir, que no la niega ni la neutraliza: la representación del aburrimiento y la estupidez hacen más evidente (por absurda e inútil) la lógica bélica de lo político, es decir, maniobra en el terreno de la política, pero funciona como táctica impolítica. En la problematización de la articulación entre aburrimiento y utopía (o la falta de esta), los afectos desplegados aquí pueden ser leídos como estrategia discursiva (im)política que filtra, entre las fisuras y porosidades de la retórica institucional de la revolución, estas representaciones negativas que son posibles estrictamente fuera de ciertas políticas y de la retórica de lo político como lógica bélica.

Tanto en Presiones y diamantes como en Pequeñas maniobras (y en muchos otros textos de diversos géneros del autor cubano) ${ }^{9}$ observamos una insistencia en la puesta en suspenso de la voluntad política y del ideal heroico. Según Thomas Anderson, Pequeñas maniobras no es un texto revolucionario; Sebastián es la antítesis del héroe revolucionario (200). ${ }^{10}$ La novela cuestiona la idea de voluntad colectiva, de antagonismo de lo político, y de la función comprometida de la literatura. Como señala Peter Hallward: "Political will, of course, involves collective action and direct participation. A democratic political will depends on the power and practice of inclusive assembly, the power to sustain a common commitment" (14). Voluntad política, el devenir histórico, la comunidad y el compromiso se neutralizan en Piñera por las figuras de la apatía, el miedo, el aburrimiento, la estupidez. Si el proletariado, como sujeto de cambio histórico, existe sólo por medio de la acción y por lo tanto es

9 Por ejemplo en su obra de teatro Dos viejos pánicos, en muchos de los Cuentos Fríos y en la novela $L a$ carne de René, entre otros.

10 Anderson interpreta Pequeñas maniobras como representación de culpa y frustración sexual relacionados a la homosexualidad de Piñera, y a la confesión textual y religiosa.

Revista Iberoamericana, Vol. LXXXII, Núm. 257, Octubre-Diciembre 2016, 819-836 ISSN 0034-9631 (Impreso) ISSN 2154-4794 (Electrónico) 
acción ("The proletariat forms itself by its day-to-day action. It exists only by action. It is action. If it ceases to act, it decomposes") ${ }^{11}$ su estatuto ontológico se desarma en la inactividad, y de esta manera se dificulta indirectamente una representación de la Historia en la cual la voluntad (del pueblo, del sujeto heroico, del proletariado, del Estado) es el motor que la vuelve posible. Este poder de voluntad y emancipación, tan presente en las ideas del Che Guevara para la teoría foquista de la revolución, supone una persistencia y continuidad de la voluntad de acción, pero además, como lo nota Hallward, se constituye en la decisión:

To continue or not to continue - this is the essential choice at stake in any militant ethics. Either you will and do something, or you do not. Even as it discovers the variety of ways of doing or not-doing, these are the alternatives a political will must confront: yes or no, for or against, continue or stop [...] (20)

Es inevitable la relación con el pensamiento de Alan Badiou en el cual la decisión, como fidelidad a un acontecimiento, es constitutiva del sujeto de una verdad. Sin embargo, en el caso de Piñera el aburrimiento, la apatía y la estupidez configuran el escándalo de lo político, una metáfora de lo indecidible que, como señala Martin Heidegger con respecto a la experiencia del aburrimiento profundo, nos deja en el "limbo" o nos deja "vacíos". La reflexión filosófica de Heidegger proporciona la posibilidad de pensar el aburrimiento en Presiones y diamantes y Pequeñas maniobras como una puesta en suspenso del mundo y del tiempo, con la finalidad de que aparezca otra experiencia (en Pequeñas maniobras es la apatía y el no-compromiso lo que lleva al aburrimiento del lector, ya que el narrador se niega a que "pasen cosas"). Aunque hay una diferencia conceptual entre aburrimiento y apatía, en ambas se deduce una distancia que provoca dejadez, desinterés y falta de vigor para la acción, es decir, lo contrario de una ética militante. Tanto en el tedio como en la apatía la puesta en suspenso del mundo sugiere una analogía con el "stop and think" de Hannah Arendt, con la diferencia de que en la experiencia del tedio y su correlato de la apatía, el resultado es la falta de compromiso, la improductividad y la pasividad. Desde esta perspectiva, cabe todavía una vuelta de tuerca en las figuras y afectos negativos que rondan estas novelas; podemos identificar una paradoja fundamental que, a mi modo de ver, constituye el escándalo de lo político mencionado anteriormente: si se considera el pensamiento como opuesto a la acción, según afirma Hannah Arendt, que nos separa del mundo y del prójimo como una operación hecha en "solitud" (en contraposición con "lonliness") que interrumpe toda actividad: "All thinking demands stop-and think" (Life 78), hay en la suspensión de la voluntad política, de la acción y por lo tanto de la Historia, una paradoja que abarca tanto a la estupidez y la apatía como a la soledad y el retiro del pensamiento:

15 Se trata de una cita de Luckàcs que Hallward menciona en su texto, 17.

Revista Iberoamericana, Vol. LXXXII, Núm. 257, Octubre-Diciembre 2016, 819-836 
And since whatever prevents thinking belongs to the world of appearances and to those of common-sense experiences I have in company with my fellow-men and that automatically guarantee my sense of realness of my own being, it is indeed as though thinking paralyzed me in much the same way as an excess of consciousness may paralyze the automatism of my bodily functions. (78-79; énfasis mío)

El aburrimiento y la falta de compromiso en Piñera evocan por una lado un exceso de conciencia, y por otro, la parálisis de la acción. Pensar supone un retiro del mundo que tiene un efecto doble y complementario ya que paraliza y al mismo tiempo suspende el automatismo que, como en las funciones del cuerpo, es acción sin reflexión. De esta manera, el pensamiento y la apatía comparten analogías estructurales, ya que los dos estados se producen en la soledad y en el retiro de la comunidad: plantean un interrogante sobre la posibilidad de reflexión política en el contexto de una lógica bélica que requiere la acción como principio ontológico del sujeto. Interrumpen una acción alienante, paralizándola y al mismo tiempo, dejando lugar para la reflexión ("it is indeed as though thinking paralyzed me" 79).

¿Es posible que los afectos negativos desplegados aquí sugieran, mediante la suspensión de la voluntad política y el retiro de la comunidad, un escándalo de lo político? Hemos señalado que la apatía y la estupidez constituyen lo indecidible, el no-compromiso (en conflicto con una voluntad política o militante definida por la decisión), ¿puede entonces haber política sin decisión? O más específicamente: ¿es la interrupción de la acción un mecanismo (im)político de la escritura? Propongo usar el paréntesis (que a la vez une y separa lo impolítico de lo político), cuando sea necesario remarcar la paradoja de este término, su "indecibilidad" con respecto a la política y a la literatura; como una forma de marcar la relación y el límite de lo impolítico y lo político.

Creo que en la escritura de Piñera el retiro del mundo, común al pensamiento pero también a la apatía de la estupidez y el aburrimiento, se afianza en la ambigüedad de lo indecidible que constituye el escándalo de lo político. La función (im)política de los afectos negativos articula dos tácticas de sentido: 1) el desarme de los antagonismos propios de lo político; 2) el escándalo de la suspensión de la voluntad o la acción política por lo "indecidible" del no-compromiso (la "resistencia pasiva" de Bartleby).

Es preciso entonces prestar atención a las "pequeñas maniobras" de no-compromiso que plantea la novela. ${ }^{12}$ Como hemos señalado, las similitudes entre Sebastián y Bartleby son muchas: "Todo puede ser un compromiso, mejor será no hacerlo" (135), dice el protagonista: "Soy el soldado desconocido de unas pequeñas maniobras, cuyo

12 En general la información de la fecha de publicación de Pequeñas maniobras es 1963. Pocas fuentes aclaran que su primera fecha de escritura es 1957, cuando Piñera estaba en Buenos Aires (Anderson). De todas maneras su contexto de publicación en la cuba posrevolucionaria es significativo para una lectura de la novela, y sería interesante compararla con otras novelas publicadas el mismo año.

Revista Iberoamericana, Vol. LXXXII, Núm. 257, Octubre-Diciembre 2016, 819-836 ISSN 0034-9631 (Impreso)

ISSN 2154-4794 (Electrónico) 
escenario son las calles de mi ciudad; su materia, mi sangre gota a gota, y mi ideal, el deseo angustioso de pasar inadvertido" (323). El narrador de estas "memorias" se define como "un estratega de pequeñas maniobras" (322) que pasa su vida evitando el compromiso, los vínculos afectivos, he incluso la narración de su propia historia: "Otro lector, con santa indignación, echando llamas por la boca se me pone adelante [...] Estoy harto de leer páginas y páginas donde el protagonista no se compromete. Acaso ignora que el hombre es compromiso, que hoy más que nunca la consigna es comprometerse" (315). Es que Sebastián tiene miedo y sus memorias podrían considerarse como un recuento de su miedo, y aún más; una manifestación de su paranoia:

Pueden irrumpir los esbirros y llevarme preso, en la iglesia, en mi casa, en la calle o en
la escuela donde gano el pan [...] Quiero aclarar que si yo hablo de esbirros por acá y
esbirros por allá no es porque yo haya cometido un hecho delictuoso. Hasta hora no he
robado ni matado. Bien, si no he hecho ni una cosa ni la otra, debo cuidarme mucho de
que los esbirros hagan recaer sus sospechas en mi persona. [...] Yo no intento grandes
hazañas para no tener que ver con los esbirros. Y así y todo es difícil escapar; cada
momento del día uno está amenazado por situaciones como ésta [...] Tiemblo de sólo
pensar que si él abriera su boca en este momento los esbirros saldrían en bandadas a
vaciar la ciudad y meterla en esas horribles celdas [...] (135-37)

Estos pensamientos que asaltan a Sebastián en todo momento, y en especial cuando debe interactuar con el prójimo, tienen similitud con una "teoría de la conspiración" que, como lo describe Sianne Ngai está relacionada con una especie de miedo, basado en "the dysphoric apprehension of a holistic and all-encompassing system" (299). La teoría de la conspiración, así como la novela de detectives, encuentra al protagonista enredado en un sistema que lo supera y que no alcanza a comprender o controlar. ${ }^{13} \mathrm{La}$ sospecha y el miedo forman parte de un mecanismo afectivo que por un lado evita el contacto con el prójimo, y por otro, antropomorfiza el "sistema" como un sujeto capaz de "comprender" a sus enemigos y de actuar en consecuencia (300). La paranoia como afecto negativo separa los cuerpos en lugar de unirlos, aísla al sujeto de la comunidad, en comunidad; como he mencionado anteriormente, provoca la figura del aislamiento en comunidad, propia de la escritura de Piñera.

Sebastián cuenta sus memorias, aunque niegue todo el tiempo este hecho evidente: "Aquí, como los novelistas de verdad podría poner una serie de puntos suspensivos. Es que han pasado cinco meses. No creo que valga la pena impresionar al lector: 'Antes de Cristo, después de Cristo...' No ha ocurrido nada que justifique una separación en el relato" (268). Pequeñas maniobras puede leerse como un meta-comentario sobre

13 " [...] like the conventional film-noir detective, belatedly find they are small subjects caught in larger systems extending beyond their comprehension and control", Ngai 299.

Revista Iberoamericana, Vol. LXXXII, Núm. 257, Octubre-Diciembre 2016, 819-836 ISSN 0034-9631 (Impreso)

ISSN 2154-4794 (Electrónico) 
la escritura misma, un texto que se auto-interpreta en lo que podría ser un exceso paranoico que intenta anticipar su propia lectura:

Prosigo con los tumbos o los palos de ciego. Quisiera poder ofrecer al lector un cuadro más animado. En estas Memorias deberían pasar cosas. De pronto el lector suspende la respiración: el protagonista se ha equivocado de sobre [..] la situación es crítica, el lector se angustia [...] Pasan veloces sus dedos por las páginas, es preciso salir cuánto antes de esta duda terrible. Por fin, el desenlace se ofrece a su vista despavorida. El lector se sorprende al escuchar su propia risa. Sucede que el novelista, dotado de "amplios recursos", de "fértil imaginación", tiene muy presente que en su relato deben pasar cosas. (255, énfasis mío)

Pero, ¿qué cosas pasan en este relato? Sebastián se esconde. Su historia es la de una evasión: a ser interpelado por los otros personajes, por la vida misma y hasta por el lector. Pequeñas maniobras es una puesta en escena de cómo la literatura escapa a las exigencias de compromiso impuestas por la voluntad política y militante, por la retórica revolucionaria y por la moral del sacrificio. Piñera lo señala en su ensayo sobre Kafka, en 1945, en el que aclara que la función de la literatura reside en el extrañamiento de la creación:

Se trata, por el contrario, de demostrar que en el campo de lo estrictamente literario el único móvil del artista es producir, a través de una expresión nueva, ese imponderable que espera todo lector y que se llama la "sorpresa literaria"; la sorpresa por invención, lo mismo que un asesino que conseguiría su objetivo mediante la muerte por envenenamiento, o del espía por traición.(“Secreto" 42)

En Pequeñas maniobras el novelista "tiene muy presente" que deben pasar cosas, y sin embargo, se niega a comprometerse con la narración y con el lector. La novela relata el escape del sujeto -y de la literatura misma- del imperativo ideológico; y en éste sentido es una escritura que no representa, que no alegoriza: es paranoica de su propia capacidad de alegorizar, de la facilidad de representación del lenguaje y por lo tanto, de su potencialidad para hegemonizar. Evita la función pedagógica y ejemplar de un compromiso político o simplemente del protagonista como héroe que representa un modelo dentro los parámetros morales de la revolución. Sebastián es la contracara del "hombre nuevo" que el Che Guevara prefigura en "El socialismo y el hombre en Cuba"; en el cual el sujeto revolucionario está siempre constituido por la moral como engranaje de la comunidad y de la Historia: "Como ya dije, en momentos de peligro extremo es fácil potenciar los estímulos morales; para mantener su vigencia, es necesario el desarrollo de una conciencia en la que los valores adquieran categorías nuevas. La sociedad en su conjunto debe convertirse en una gigantesca escuela" (Guevara 14). La acción revolucionaria y la conciencia de su deber social son las

Revista Iberoamericana, Vol. LXXXII, Núm. 257, Octubre-Diciembre 2016, 819-836 ISSN 0034-9631 (Impreso) ISSN 2154-4794 (Electrónico) 
bases para este hombre nuevo, así como el sacrificio ("El individuo de nuestro país sabe que la época gloriosa que le toca vivir es de sacrificio; conoce el sacrificio. Los primeros lo conocieron en la Sierra Maestra y dondequiera que se luchó; después lo hemos conocido en toda Cuba" (Guevara 20)). y sobre todo la acción como condición ontológica del sujeto revolucionario: "Nos forjaremos en la acción cotidiana, creando un hombre nuevo con una nueva técnica" (Guevara 20). Punto por punto Sebastián representa el anti-héroe revolucionario, pero aún más: palabra por palabra la novela de Piñera plantea una experiencia de pasividad y evasión en la que la literatura no responde con el compromiso a la interpelación de lo político.

Rita Molinero interpreta Pequeñas maniobras y La carne de René como novelas que comparten un "síndrome masoquista", en el cual la "estética de la suspensión" constituye una manera de crear una realidad ideal, lo que Piñera llama "FUGA". Según Molinero, esta es una manera de "suspender los horrores de la realidad" para retirarse a regiones imaginarias (330). Sin embargo, en las novelas que analizamos no existe un escape hacia mundos ideales sino más bien una interrupción de cualquier ficción utópica, ya sea de la ficción de lo político o de la comunidad. En las novelas que analizamos aquí se puede rastrear una insistencia en la experiencia del tedio, la apatía, la repetición alienante. El aburrimiento se presenta como distanciamiento: del deseo, las relaciones amorosas, el trabajo, la creatividad o la fidelidad a una idea, el activismo o la voluntad política. Interrumpe la comunicación y los lazos entre sujetos, el compromiso afectivo o ideológico, la continuación de la narración (en la que el lector está harto de que no pase nada) el interés general de obtener un beneficio, el valor de cualquier objeto (incluso el diamante más valioso de la tierra) o meta. Si pudiéramos, a la manera de un panóptico, observar al mismo tiempo a todos los personajes de las novelas y relatos de Piñera, los veríamos subiendo y bajando una escalera sin fin, viajando en círculos en un cochecito de bebé o una cazuela, escuchando el relato interminable de fotografías invisibles, mascando chicles, jugando canasta silenciosa, congelándose en bloques de hielo, escribiendo la misma frase un millón de veces, nadando en seco, evitando el placer y el dolor, negándose una y otra vez a comprometerse. ${ }^{14}$ Como autómatas, repitiendo los mismos gestos absurdos e inquietantes; simulacros de afectos, de ideas, de relaciones sociales: crean un vacío que, irónicamente, sugiere que deberían pasar cosas. ¿Pueden leerse como síntoma de un deseo utópico? En un sentido literal, la lectura de Molinero interpreta la escritura como un antídoto contra lo real, punto de partida hacia mundos imaginarios; pero ¿cómo identificar estos mundos? Resulta productiva la conexión entre aburrimiento y utopía como figuras que plantean la experiencia de la posibilidad, lo que Peter Osborne identifica como una similitud entre el "aburrimiento

${ }^{14}$ Me refiero aquí a cuentos como "El álbum", "El viaje", "La gran escalera del palacio legislativo", "El filántropo". Para un análisis que incluya estos cuentos véase mi trabajo Escrituras Impolíticas (en revisión).

Revista Iberoamericana, Vol. LXXXII, Núm. 257, Octubre-Diciembre 2016, 819-836 ISSN 0034-9631 (Impreso)

ISSN 2154-4794 (Electrónico) 
profundo" (Heidegger) en el que "la posibilidad del 'whatever' se hace posible"; y la estructura de la utopía anclada en la "posibilización”, es decir la presentación de algo que todavía no está presente: "Possibility is the privileged mode of utopian thought. Indeed is the modal condition of politics in general" (37). Osborne señala a la posibilidad como una característica compartida entre el aburrimiento profundo y la utopía: "There is an utopian function to boredom in modernity as the basis of a distinctive experience of possibility" (37). Desde este punto de vista, el aburrimiento y la apatía presentan distopías, que funcionan de manera (im)política, ya que suspenden la lógica de lo político y de la moral del compromiso revolucionario. En la escritura de Piñera podríamos decir entonces, en una vuelta de tuerca a las frases de Clausewitz y de Foucault, que el aburrimiento es la continuación de la política por otros medios. ${ }^{15}$ Walter Benjamin afirma que nos aburrimos porque no sabemos qué estamos esperando; en esa suspensión de la Historia radica justamente, la "posibilización”. "Boredom is the threshold to great deeds. -Now, it would be important to know: What is the dialectical antithesis of boredom? (Benjamin 105) Me arriesgo a proponer que, en la escritura de Piñera, la lógica bélica de lo político es la respuesta a la pregunta de Benjamin. Es decir: el aburrimiento es la suspensión de la guerra y la continuación de la política por medios (im)políticos.

\section{BiBLIOGRAFÍA}

Althusser, Louis. On Ideology. New York: Verso, 2008.

Anderson, Thomas F. Everything in its Place. The Life and Works of Virgilio Piñera.

Lewisburg: Bucknell UP, 2006.

Arendt, Hannah. The Life of the Mind. New York: Harcourt Brace \& Company,1978. Beasley-Murray, Jon. Posthegemony. Minneapolis: U of Minnesota P, 2010.

Benjamin, Walter. The Arcades Project. Howard Eiland y Kevin McLaughlin, trads. Cambridge: The Belknap Press of Harvard UP, 2003.

Buck-Morss, Susan. Dreamworld and Catasthrophe. Masachussetts: MIT Press, 2002. Buelens, Gert y Dominiek Hoens. "Above and Beneath Classification." Diacritics: Taking Exception to the Exception 37/2-3 (Summer-Fall 2008): 157-70.

Duchesne-Winter, Juan. La guerrilla narrada: acción, acontecimiento, sujeto. San Juan: Callejón, 2010.

Espinosa, Carlos, ed. Virgilio Piñera en persona. Habana: Unión, 2003.

Esposito, Roberto. Categorías de lo impolitico. Roberto Raschella, trad. Buenos Aires: Katz, 2006.

${ }^{15}$ En Society Must be Defended, Foucault revierte la frase de Clausewitz y afirma: "Politics is the continuation of war by other means".

Revista Iberoamericana, Vol. LXXXII, Núm. 257, Octubre-Diciembre 2016, 819-836 ISSN 0034-9631 (Impreso)

ISSN 2154-4794 (Electrónico) 
Flatley, Jonathan. Affective Mapping. Melancholia and The Politics of Modernism. Cambridge: Harvard UP, 2008.

Foucault, Michel. Society must be Defended. David Macey, trad. New York: Picador, 2003.

Guevara, Ernesto. "El socialismo y el hombre en Cuba". 1965. <http://www.marxists. org/espanol/guevara/65-socyh.htm>. 14 ago. 2016.

Hallward, Peter. "Radical Politics and Political Will." Radical Politics Today. 2009. $<$ http://eprints.kingston.ac.uk/15768/1/HAllward-P-15768.pdf>. 14 ago. 2016.

Heidegger, Martin. The Fundamental Concepts of Metaphysics. World, Finitude, Solitude. William McNeil y Nicholas Walker, trads. Bloomington: Indiana UP, 1995.

Holguín, Valerio. Virgilio Piñera: una poética de la frialdad. London: UP of America, 1997.

Luna, Noel. "Virgilio Piñera contra la poesía". La Habana elegante. <http://www. habanaelegante.com/Fall_Winter_2012/Dossier_Pinera_Luna.html>.

Melville, Herman. Bartleby el escribiente. <http://edu.mec.gub.uy/biblioteca_digital/ libros/M/Melville, \%20Herman\%20-\%20Bartleby\%20el\%20escribiente.pdf>. 14 ago. 2016.

Ngai, Sianne. Ugly Feelings. Cambridge: Harvard UP, 2005.

Molinero, Rita, ed. Virgilio Piñera: la memoria del cuerpo. San Juan: Plaza Mayo, 2002. Osborne, Peter. "The Dreambird of Experience. Utopia, Possibility, Boredom." Radical Philosophy 137 (May/June 2006): 36-44.

Piñera, Virgilio. Presiones y diamantes. Pequeñas maniobras. Habana: Unión, 2002. "El secreto de Kafka". 1945. <https:/hoteltelegrafo.blogspot.com/2012/08/ el-secreto-de-kafka.html>. 14 ago. 2016.

Quintero-Herencia, Juan Carlos. Fulguración del espacio. Letras e imaginario institucional de la Revolución Cubana (1960-1971). Rosario: Beatriz Viterbo, 2002.

Schmitt, Carl. The Concept of the Political. George Schwab, trad. Chicago: U of Chicago P, 1996. 